Подригало М.А., Полянський О.С., Подригало Н.М., Байцур М.В.

Харківський начіональний автомобільно-дорожній університет

\title{
ВПЛИВ ПОДАТЛИВОСТІ ЛАНОК НА ККД МЕХАНІЗМІВ І МАШИН
}

\begin{abstract}
В роботі запропоновано новий метод оцінки впливу податливості ланок на ККД механізмів і машин. Встановлено, що податливість елементів механізмів і машин слід враховувати при оцінці внутрішніх втрат енергії і визначенні ККД. Отримано аналітичні вирази, що дозволяють оцінити вплив наведених жорсткостей, моментів інерції і сил тертя на внутрішні втрати енергії в механізмі. Визначено взаємозв'язок між деформацією ланок і ККД механізмів і машин. Запропоновано новий показник (пружний ККД), що дозволяє розрахувати циклової і миттєвий ККД механізмів і машин 3 податливими ланками з урахуванням втрат в переміщенні і швидкості через пружну деформацію ланок.

Ключові слова: механізм, нерівномірний режим руху, пружні деформації ланок, втрати енергії, оцінка коефіцієнта корисної дії.
\end{abstract}

Постановка проблеми. Механічний ККД (коефіцієнт корисної дії) - це один з найважливіших якісних показників роботи машини, який показує, яка частина сумарної підведеної енергії корисно використовується в пристрої, будучи, таким чином, найбільш загальним показником економічності перетворення енергії машин, устаткування, приладів та інших виробів.

Відомо, що ККД визначають 3 урахуванням втрат на тертя, що знижують сили і моменти на вихідних ланках механізмів. При цьому деформація ланок в процесі роботи механізму при визначенні ККД зовсім не враховується. Пов'язано це з тим, що ланки механізму в таких випадках розглядаються 3 позиції класичної механіки як тверде тіло, відстань між точками якого не змінюється.

В даній статті запропоновано метод визначення коефіцієнта корисної дії машин і механізмів, що враховує податливість (деформацію) їх ланок.

Аналіз останніх досліджень. Розрізняють [1] миттєвий і циклової ККД. Миттєвий ККД - це відношення корисної потужності $N_{\text {п }}$ знімається з веденої ланки, до потужності зовнішніх (рушійних) сил $N_{\text {дв}}$, витраченої на провідній ланці. Цикловий ККД - це відношення витрат корисної роботи $A_{\text {п }}$ до витрат роботи рушійних сил $A_{\text {дв }}$ за цикл сталого руху. Таким чином, миттєвий і циклової ККД пристрою можуть бути визначені наступним чином

$$
\begin{gathered}
\eta^{\mathrm{MГH}}=\frac{N_{\text {ПІ }}}{N_{\text {дв }}} ; \\
\eta^{\mathrm{MГH}}=\frac{A_{\text {П }}}{A_{\text {дв }}} .
\end{gathered}
$$

При розрахунку миттєвого ККД механізму можна використовувати як значення потужностей в даний момент часу, так і середні значення, визначені за цикл сталого руху. В останньому випадку миттєвий ККД буде дорівнює цикловому. При нерівномірному русі ланок механізму в певні моменти часу миттєвий ККД може приймати значення більше одиниці. Це суперечить фізичному змісту ККД, і в такому разі його можна розглядати як коефіцієнт динамічності [2]. Враховуючи останню обставину можна стверджувати, що циклової ККД (в ситуації, коли переважає нерівномірний режим руху машини або механізму) $є$ найбільш коректним якісним і кількісним показником роботи.

Оскільки, як вже зазначалося, рівномірний режим руху машин і механізмів зустрічається рідко, то визначення ККД через відношення сил або моментів на вихідному $\left(F_{2}, T_{2}\right)$ і вхідному $\left(F_{1}, T_{1}\right)$ ланках з урахуванням передавального відносини $€$ неточним. В роботі [3] запропоновано залежність для такого визначення ККД

$$
\eta=\left|\frac{F_{2}}{F_{1} \cdot U_{1-2}}\right|=\left|\frac{T_{2}}{T_{1} \cdot U_{1-2}}\right|,
$$

$U_{1-2}$ - передавальне відношення механізму. 
В роботах $[1,4,5,6]$ зазначається, що в процесі роботи ланки зазнають деформації під впливом передаються навантажень, в результаті чого потенційна енергія пружних ланок переходить в теплову енергію. Такі втрати енергії мають місце в пружному контакті коліс фрикційних механізмів, в гнучких ланках відповідних механізмів (в ремінних передачах). Відносні значення цих втрат залежать від пружних властивостей матеріалу ланки і його навантаженості. При цьому наголошується, що в теорії механізмів і машин розглядаються тільки втрати в кінематичних парах, тобто втрати на тертя [1].

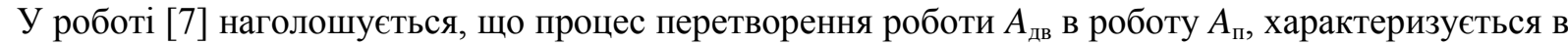
загальному вигляді енергетичним коефіцієнтом корисної дії, не показує основного принципу цього

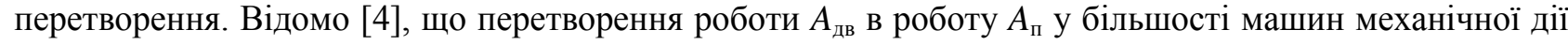

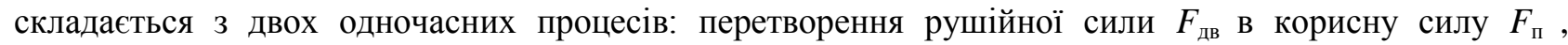
машиною на ії виконавчому органі; перетворення переміщення $S$, сприймається машиною від дії сили

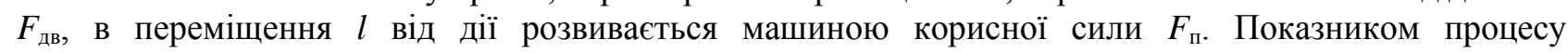
перетворення сили служить ставлення

$$
k=\frac{F_{\text {дв }}}{F_{\text {п }}},
$$

де $F_{\text {дв }}$ - рушійна сила;

$F_{\text {п }}$ - сила корисного опору.

Дане ставлення, що характеризує силовий динамічний ефект роботи машини, називають коефіцієнтом перетворення сили.

Характер процесу перетворення переміщень оцінюють ставленням

$$
m=\frac{S}{l}
$$

де $S$ - лінійне переміщення елемента, що рухається машину;

$l$ - переміщення виконавчого (робочого) органу машини.

Коефіцієнт $m$ характеризує кінематичний ефект роботи даної машини i називається коефіцієнтом перетворення (передачі) переміщень або передаточним числом переміщень крайніх елементів машини. Звідси випливає, що

$$
\eta=\frac{A_{\Pi}}{A_{\text {дв }}}=\frac{1}{k \cdot m}
$$

або

$$
\eta \cdot m \cdot k=1
$$

В роботі [7] також наголошується, що наведені вище коефіцієнти комплексно характеризують процес роботи машини шляхом перетворення енергії, сил і руху. Рівність (7) служить для перевірки достовірності експериментально визначених коефіцієнтів, що характеризують рівень корисності досліджуваної машини.

Слід зазначити, що силові втрати, викликані тертям в кінематичних парах, впливають на ставлення $k$ и $\eta$. Однак, у відомих дослідженнях не розглянуто питання впливу деформацій ланок механізмів на ставлення $m$, що призводить до неточної оцінки коефіцієнта корисної дії $\eta$.

Впливу пружних та інерційних ланок на ККД трансмісії тракторно-тягових машин присвячено дослідження [8]. Запропонована залежність для розрахунку загального ККД трансмісії, що враховує дисипативні втрати, втрати на розгін обертових мас і пружні втрати, викликані деформацією валів. Ця залежність має вигляд

$$
\eta_{\text {тр }}=\eta_{\text {тр }}^{\text {дис }} \cdot \eta_{\mathrm{tp}}^{\text {упр }}=\left(\eta_{\mathrm{tp}}^{\mathrm{c \tau}}+\eta_{\mathrm{Tp}}^{\text {кин }}+\eta_{\mathrm{Tp}}^{\text {дин }}-2\right) \eta_{\mathrm{Tp}}^{\text {упр }}
$$

де $\eta_{\text {тр }}^{\text {дис }}-$ ККД, що враховує дисипативні втрати в трансмісії; 
$\eta_{\text {тр }}^{\text {ст }}, \eta_{\text {тр }}^{\text {кин }}-$ ККД, що враховують дисипативні втрати, обумовлені сухим і в'язким тертям, відповідно;

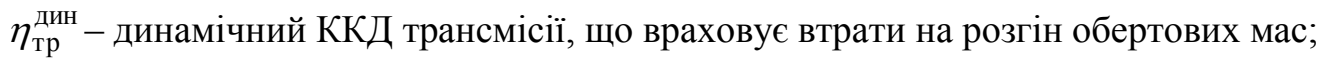

$\eta_{\text {тр }}^{\text {упр }}$ пружний ККД трансмісії, що враховує пружні деформації валів.

Однак, ці результати потребують узагальнення, що дозволяє здійснювати розрахунки коефіцієнта корисної дії машин і механізмів з урахуванням пружних деформацій їх ланок.

Формування цілей роботи. Метою дослідження є розробка методу оцінки впливу податливості ланок на ККД механізмів i машин. Для досягнення поставленої мети необхідно визначити взаємозв'язок між деформацією ланок і ККД механізмів і машин.

Основна частина. Будь-який механізм або машину можна уявити як систему з зосередженими параметрами (див. рис.1). На рисунку наведена динамічна модель механізму, в якій всі пружні і інерційні ланки представлені наведеної жорсткістю $c_{\text {пр }}$ i наведеною масою $m_{\text {пр }}$.

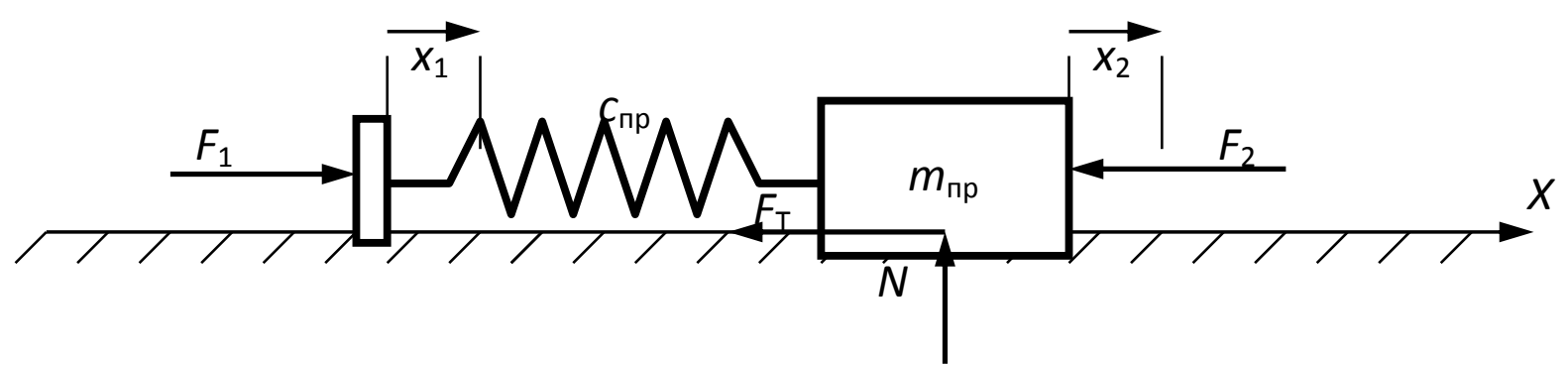

Рисунок 1. Динамічна модель механізму з деформованими ланками

Розглянемо варіант навантаження розглянутої моделі, при якому $F_{1}=$ const,$F_{2}=$ const. $\mathrm{У}$ початковий момент часу $(t=0)$ сили $F_{1}$ і $F_{2}$ досягли свого максимального значення. Сила $F_{1}$, впливаючи на шайбу, здійснює переміщення лівого кінця пружини на відстань $x_{1}$, яке можна визначити як

$$
x_{1}=k_{x_{1}} \cdot t,
$$

де $k_{x_{1}}-$ кутовий коефіцієнт прямий $x_{1}(t)$ (швидкість переміщення шайби).

Робота сили $F_{1}$ на вході механізму

$$
A_{1}=A_{\text {дв }}=F_{1} \cdot x_{1 \max },
$$

де $x_{1 \max }-$ максимальне переміщення вхідної ланки механізму.

Робота сили $F_{2}$ на виході механізму

$$
A_{2}=A_{\Pi}=F_{2} \cdot x_{2 \max },
$$

де $x_{2 \max }-$ максимальне переміщення вихідної ланки механізму.

Цикловий ККД механізму

$$
\eta^{\text {цикл }}=\frac{A_{\text {П }}}{A_{\text {дв }}}=\frac{F_{2}}{F_{1}} \cdot \frac{x_{2 \max }}{x_{1 \max }} .
$$

Форма запису виразів (10) - (12) коректна, оскільки ми прийняли, що $F_{1}=$ const i $F_{2}=$ const. Розглядаючи рівновагу динамічної системи, визначимо

$$
F_{1}=F_{2}+F_{\mathrm{T}}=F_{2}+f \cdot N=F_{2}+f \cdot m_{\text {пр }} \cdot g,
$$

де $F_{\mathrm{T}}$ - сила тертя (дисипативний зв'язок в механізмі),

$$
F_{\mathrm{T}}=f \cdot N=f \cdot m_{\text {пр }} \cdot g ;
$$

$f$ - коефіцієнт тертя ковзання; 
$N$ - нормальна реакція опори на ланцюг $m_{\text {пр }}$,

$$
N=m_{\text {пр }} \cdot g
$$

Зусилля пружини при досягненні $x_{1 \max }$ i $x_{2 \max }$

$$
P_{\text {пр }}=c_{\text {пр }}\left(x_{1 \max }-x_{2 \max }\right)=F_{1}=F_{2}+f \cdot m_{\text {пр }} \cdot g \cdot
$$

3 виразу (16) визначимо

$$
x_{2 \max }=x_{1 \max }-\Delta x=x_{1 \text { max }}-\frac{F_{1}}{c_{\text {пр }}}=x_{1 \text { max }}-\frac{F_{2}+f \cdot m_{\text {пр }} \cdot g}{c_{\text {пр }}},
$$

де $\Delta x$ - різниця переміщень вхідного і вихідного ланок механізму.

Підставляючи вирази (13) і (17) в співвідношення (12), отримаємо

$$
\eta^{\text {цикл }}=\frac{F_{1}-f \cdot m_{\text {пр }} \cdot g}{F_{1}} \cdot\left(\frac{x_{1 \max }-\frac{F_{1}}{c_{\text {пр }}}}{x_{1 \max }}\right)=\eta_{f}^{\text {цикл }} \cdot \eta_{\text {упр }}^{\text {цикл }},
$$

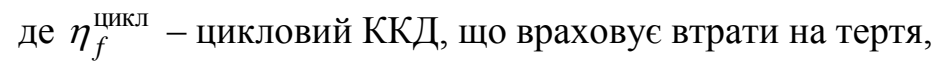

$$
\eta_{f}^{\text {цикл }}=\frac{F_{1}-f \cdot m_{\text {пр }} \cdot g}{F_{1}}=1-\frac{f \cdot m_{\text {пр }} \cdot g}{F_{1}},
$$

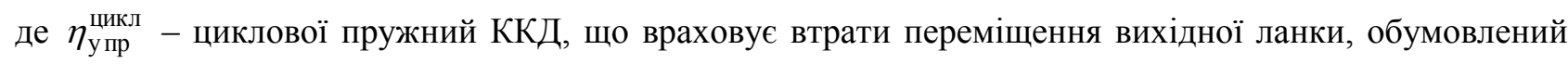
втратами на деформації ланок механізму [5],

$$
\eta_{\text {упр }}^{\text {цикл }}=\frac{F_{1}-f \cdot m_{\text {пр }} \cdot g}{F_{1}}=1-\frac{F_{1}}{c_{\text {пр }} \cdot x_{1 \max }} .
$$

Аналізуючи рівняння (20), можна зробити висновок про те, що для абсолютно жорсткої системи

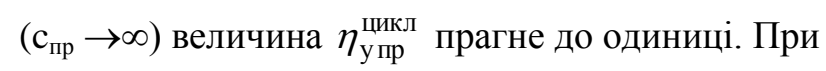

$$
F_{1}=c_{\text {пр }} \cdot x_{1 \max }
$$

величина $\eta_{\text {упр }}^{\text {цикл }}=0$.

Таким чином, проведені нами дослідження показали, що податливість елементів (ланок) механізмів і машин слід враховувати при оцінці внутрішніх втрат енергії в механізмах і машинах $\mathrm{i}$ визначенні ККД. Слід також зазначити, що класичні курси теоретичної механіки і теорії механізмів і машин, вивчаючи абсолютно тверде тіло, не розглядають динаміку механізмів і машин 3 податливими (деформованими) ланками. Тому, переходячи від загальноінженерних дисциплін до спеціальних, студенти вищих технічних навчальних закладів не готові до сприйняття теорії спеціальних машин і механізмів, в якій це враховується.

Визначимо миттєвий ККД трансмісії моделі механізму (див. рис.1). Для даної моделі миттєвий ККД може бути визначений як

$$
\eta^{\mathrm{мг \textrm {H }}}=\frac{F_{2} \cdot \dot{x}_{2}}{F_{1} \cdot \dot{x}_{1}},
$$

де $\dot{x}_{1}, \dot{x}_{2}$ - швидкості переміщення вхідної та вихідної ланок, 


$$
\dot{x}_{1}=\frac{\partial x_{1}}{\partial t}=k_{x_{1}}
$$

Рівняння динаміки поступального руху наведеної маси $m_{\text {пр }}$

$$
m_{\text {пр }} \cdot \ddot{x}_{2}=P_{\text {пр }}-F_{2}-f \cdot N,
$$

де $P_{\text {пр }}$ - зусилля стиснення пружини,

$$
P_{\text {пр }}=c_{\text {пр }}\left(x_{1}-x_{2}\right)=c_{\text {пр }} \cdot k_{x_{1}} \cdot t-c_{\text {пр }} \cdot x_{2} \cdot
$$

Підставляючи вирази (15) і (24) в рівняння (25), отримаємо

$$
m_{\text {пр }} \cdot \ddot{x}_{2}+c_{\text {пр }} \cdot x_{2}=c_{\text {пр }} \cdot k_{x_{1}} \cdot t-\left(F_{2}+f \cdot m_{\text {пр }} \cdot g\right)
$$

або

$$
\ddot{x}_{2}+k_{\text {пр }}^{2} \cdot x_{2}=k_{\text {пр }}^{2} \cdot k_{x_{1}} \cdot t-\left(\frac{F_{2}+f \cdot m_{\text {пр }} \cdot g}{m_{\text {пр }}}\right),
$$

де $k_{\text {пр }}$ - кругова частота власних коливань пружної системи.

Рішення неоднорідного диференціального рівняння другого порядку має вигляд

$$
x_{2}=A_{1} \cos \left(k_{\text {пр }} \cdot t\right)+A_{2} \sin \left(k_{\text {пр }} \cdot t\right)+\frac{c_{\text {пр }} \cdot k_{x_{1}}}{k_{\text {пр }}^{2} \cdot m_{\text {пр }}} t-\frac{F_{2}+f \cdot m_{\text {пр }} \cdot g}{k_{\text {пр }}^{2} \cdot m_{\text {пр }}} .
$$

3 урахуванням граничних умов (при $t=0$ величини $\dot{x}_{2}=0$ и $x_{2}=0$ ) одержали

$$
x_{2}=\frac{c_{\text {пр }} \cdot k_{x_{1}}}{k_{\text {пр }}^{2} \cdot m_{\text {пр }}}\left[t-\frac{\sin \left(k_{\text {пा }} \cdot t\right)}{k_{\text {пр }}}\right]-\frac{F_{2}+f \cdot m_{\text {пр }} \cdot g}{k_{\text {пр }}^{2} \cdot m_{\text {пр }}}\left[1-\cos \left(k_{\text {пр }} \cdot t\right)\right] .
$$

Швидкість переміщення вихідної ланки

$$
\dot{x}_{2}=\frac{\partial x_{2}}{\partial t}=\frac{c_{\text {пр }} \cdot k_{x_{1}}}{k_{\text {пр }}^{2} \cdot m_{\text {пр }}}\left[1-\cos \left(k_{\text {пр }} \cdot t\right)\right]-\frac{F_{2}+f \cdot m_{\text {пр }} \cdot g}{k_{\text {пр }} \cdot m_{\text {пр }}} \sin \left(k_{\text {пр }} \cdot t\right) .
$$

Висловлювати $F_{2}$ через $F_{1}$ с допомогою рівності (13), отримаємо

$$
\dot{x}_{2}=\frac{c_{\text {пр }} \cdot k_{x_{1}}}{k_{\text {пр }}^{2} \cdot m_{\text {пр }}}\left[1-\cos \left(k_{\text {пр }} \cdot t\right)\right]-\frac{F_{1}}{k_{\text {пр }} \cdot m_{\text {пр }}} \sin \left(k_{\text {пр }} \cdot t\right) .
$$

3 урахуванням того, що $k_{\text {пр }}^{2}=\frac{c_{\text {пр }}}{m_{\text {пр }}}$, отримаємо

$$
\dot{x}_{2}=k_{x_{1}}\left[1-\cos \left(\sqrt{\frac{c_{\text {пр }}}{m_{\text {пр }}}} \cdot t\right)\right]-\frac{F_{1}}{\sqrt{c_{\text {пр }} \cdot m_{\text {пр }}}} \sin \left(\sqrt{\frac{c_{\text {пр }}}{m_{\text {пр }}}} \cdot t\right) .
$$

Вираз (22) для визначення миттєвого ККД з урахуванням рівнянь (23), (13) і (32) прийме вигляд 


$$
\eta^{\text {мгн }}=\frac{F_{1}-f \cdot m_{\text {пр }} \cdot g}{F_{1}}\left[1-\cos \left(\sqrt{\frac{c_{\text {пр }}}{m_{\text {пр }}}} \cdot t\right)-\frac{F_{1}}{k_{x_{1}} \sqrt{c_{\text {пр }} \cdot m_{\text {пр }}}} \sin \left(\sqrt{\frac{c_{\text {пр }}}{m_{\text {пр }}}} \cdot t\right)\right] .
$$

Рівняння (33) можна уявити у вигляді

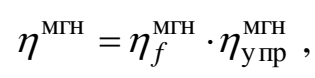

де $\eta_{f}^{\text {мгн }}$ - миттєвий ККД, що враховує втрати на тертя (силовий ККД); для даної динамічної моделі $\eta_{f}^{\text {мгн }}=\eta_{f}^{\text {цикл } ; ~}$

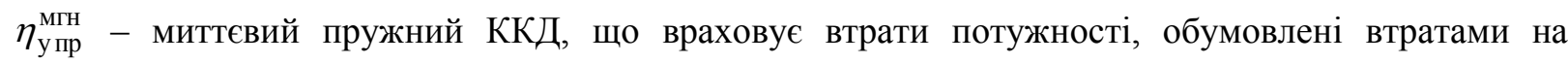
деформації ланок механізму,

$$
\eta_{\text {упр }}^{\text {мгн }}=1-\cos \left(\sqrt{\frac{c_{\text {пр }}}{m_{\text {пр }}}} \cdot t\right)-\frac{F_{1}}{k_{x_{1}} \sqrt{c_{\text {пр }} \cdot m_{\text {пр }}}} \sin \left(\sqrt{\frac{c_{\text {пр }}}{m_{\text {пр }}}} \cdot t\right) .
$$

Аналіз залежності (35) показує, що при $t=0$ i $\eta_{\text {упр }}^{\text {мгн }}=0$. Це означає, що в початковий момент часу передача потужності від вхідної до вихідної ланки відсутня. При виконанні умови

$$
\sqrt{\frac{c_{\text {пр }}}{m_{\text {пр }}}} \cdot t=\frac{\pi}{2}
$$

миттєвий пружний ККД динамічної моделі механізму (машини) може бути визначений як

$$
\eta_{\text {упр }}^{\text {мгн }}=1-\frac{F_{1}}{k_{x_{1}} \sqrt{c_{\text {пр }} \cdot m_{\text {пр }}}} .
$$

При

$$
F_{1}=k_{x_{1}} \sqrt{c_{\text {пр }} \cdot m_{\text {пр }}}
$$

величина $\eta_{\text {упр }}^{\text {мгн }}=0$ у зазначеній точці.

Максимальний час $t_{\max }$ відповідає часу протікання процесу і може бути визначено з рівняння

$$
t_{\max }=x_{1 \max } / k_{x_{1}} .
$$

Після підстановки (39) в (35) отримаємо

$$
\eta_{\text {упр }}^{\text {мгн }}=1-\cos \left(\sqrt{\frac{c_{\text {пр }}}{m_{\text {пр }}}} \cdot \frac{x_{1 \max }}{k_{x_{1}}}\right)-\frac{F_{1}}{k_{x_{1}} \sqrt{c_{\text {пр }} \cdot m_{\text {пр }}}} \sin \left(\sqrt{\frac{c_{\text {пр }}}{m_{\text {пр }}}} \cdot \frac{x_{1 \max }}{k_{x_{1}}}\right) .
$$

Очевидно, що обмеженням переміщення вхідної ланки буде умова

або з урахуванням (39)

$$
t_{\max } \leq \frac{\pi}{2} \sqrt{\frac{m_{\text {пр }}}{c_{\text {пр }}}}
$$




$$
x_{1 \max } \leq \frac{\pi \cdot k_{x_{1}}}{2} \sqrt{\frac{m_{\text {пр }}}{c_{\text {пр }}}} .
$$

Отримані вирази (18) - (20) і (33) - (35) дозволяють визначити циклової ККД і миттєвий ККД механізмів і машин, що включають в себе податливі (деформуючі) ланки.

Висновки. Податливість ланок впливає на втрати енергії в механізмах і машинах, проте у відомих дослідженнях зазначеному питанню приділено недостатньо уваги.

Отримані аналітичні вирази дозволяють оцінити вплив наведених жорсткостей, моментів інерції і сил тертя на внутрішні втрати енергії.

Використання нового показника-пружного ККД, дозволяє розрахувати циклової і миттєвий ККД механізмів і машин 3 податливими ланками 3 урахуванням втрат в переміщенні і швидкості через пружної деформації ланок.

Класичні курси теоретичної механіки, теорії механізмів і машин, опору матеріалів розглядають або абсолютно тверде тіло, або деформоване тіло в статиці. Динаміка механізмів і машин 3 деформованими ланками розглядається тільки в спеціальних курсах, що створює додаткові труднощі у студентів, приступають до їх вивчення. На наш погляд, необхідно створювати новий навчальний курс «Динаміка механізмів і машин з деформованими ланками, або новий розділ в класичному курсі теорії механізмів і машин.

1. Заблонский К.И. Теория механизмов и машин / К.И.Заблонский, И.М.Белоконев, Б.М.Щекин. - К.: Вища школа, 1989. $-376 \mathrm{c}$.

2. Подригало Н.M. Параметры динамического нагружения трансмиссий тягово-транспортных машин / Н.М.Подригало // Збірник наукових праць ПолтНТУ. Серія: Галузеве машинобудування, будівництво. - Полтава: ПолтНТУ, 2013. - Вип. 1 (16). - С. 101-105.

3. Крайнев А.Ф. Словарь-справочник по механизмам - 2-е изд. / А.Ф.Крайнев. - М.: Машиностроение, 1987. - 560 c.

4. Кожевников С.Н. Динамика машин с упругими звеньями / С.Н.кожевников. - К.: Изд-во АН УССР, 1961. - 160 с.

5. Коловский М.З. Динамика машин: Монография / М.З.коловский. - Л.: Машиностроение, 1989. -263 с.

6. Горский Б.Е. Динамическое совершенствование механических систем/ Б.Е.Горский - К.: Віпол, 1995. -290 с.

7. Федюкин В.К. Основы квалиметрии. Управление качеством продукции: учебное пособие / В.К.Федюкин. - М.: Информационно-издательский дом «Филинъ», 2004. - 296 с.

8. Подригало Н.М. Влияние упругих и инерционных звеньев на КПД трансмиссии транспортно-тяговых машин / Н.М.Подригало // Автомобильный транспорт: сб. науч. тр. - Х.: ХНАДУ, 2015. - Вып. 36. - С. 93-98.

\section{REFERENCES} 1989. $-376 \mathrm{~s}$

1. Zablonskiy K.I. Teoriya mehanizmov i mashin / K.I.Zablonskiy, I.M.Belokonev, B.M.Schekin. - K.: Vischa shkola,

2. Podrigalo N.M. Parametryi dinamicheskogo nagruzheniya transmissiy tyagovo-transportnyih mashin/ N.M.Podrigalo // Zbirnyk naukovykh prats PoltNTU. Seriia: Haluzeve mashynobuduvannia, budivnytstvo. - Poltava: PoltNTU, 2013. - Vyp. 1 (16). S. 101-105.

3. Kraynev A.F. Slovar-spravochnik po mehanizmam - 2-e izd. / A.F.Kraynev. - M.: Mashinostroenie, 1987. - 560 s.

4. Kozhevnikov S.N. Dinamika mashin s uprugimi zvenyami / S.N.kozhevnikov. - K.: Izd-vo AN USSR, 1961. - 160 s.

5. Kolovskiy M.Z. Dinamika mashin: Monografiya / M.Z.kolovskiy. - L.: Mashinostroenie, 1989. - $263 \mathrm{~s}$.

6. Gorskiy B.E. Dinamicheskoe sovershenstvovanie mehanicheskih system / B.E.Gorskiy - K.: Vipol, 1995. - 290 s.

7. Fedyukin V.K. Osnovyi kvalimetrii. Upravlenie kachestvom produktsii: uchebnoe posobie / V.K.Fedyukin. - M.: Informatsionno-izdatelskiy dom «Filin'», 2004. - 296 s.

8. Podrigalo N.M. Vliyanie uprugih i inertsionnyih zvenev na KPD transmissii transportno-tyagovyih mashin/ N.M.Podrigalo // Avtomobilnyiy transport: sb. nauch. tr. - H.: HNADU, 2015. - Vyip. 36. - S. 93-98.

Подригало М.А., Полянский А.С., Подригало Н.М., Байцур М.В. Влияние податливости звеньев на КПД механизмов и машин

В работе предложен новый метод оценки влияния податливости звеньев на КПД механизмов и машин. Установлено, что податливость элементов механизмов и машин нужно учитывать при оценке внутренних потерь энергии и определении КПД. Получень аналитические выражения, позволяющие оченить влияние приведенных жесткостей, моментов инерции и сил трения на внутренние потери энергии в механизме. Определена взаимосвязь между деформацией звеньев и КПД механизмов и машин. Предложен новый показатель (упругий КПД), что позволяет рассчитать иикловой и мгновенный КПД механизмов и машин с податливыми звеньями с учетом потерь в перемещении и скорости через упругую деформачию звеньев.

Ключевые слова: механизм, неравномерный режим движения, упругие деформации звеньев, потери энергии, оценка коэффициента полезного действия. 

machines

M. Podrigalo, A. Polyansky, N. Podrigalo, M. Baytsur. Influence of links flexibility on efficiency of mechanisms and

The paper proposes a new method for assessing the influence of link flexibility on the efficiency of mechanisms and machines. It has been established that the compliance of the elements of mechanisms and machines should be taken into account when assessing the internal energy loss and determining the efficiency. Analytical expressions are obtained that allow one to estimate the effect of reduced stiffnesses, moments of inertia, and friction forces on the internal energy loss in the mechanism. The relationship between the deformation of the links and the efficiency of the mechanisms and machines is determined. A new indicator has been proposed (elastic efficiency), which allows to calculate the cyclic and instantaneous efficiency of mechanisms and machines with ductile links, taking into account losses in displacement and speed due to the elastic deformation of the links.

Keywords: mechanism, non-uniform mode of movement, elastic deformation of links, energy loss, estimation of efficiency.

\section{АВТОРИ:}

ПОДРИГАЛО Михаіл Абович, доктор технічних наук, завідувач кафедри технології машинобудування і ремонту машин, Харківський національний автомобільно-дорожній університет, e-mail:pmikhab@gmail.com

ПОЛЯНСЬКИЙ Олександр Сергійович, доктор технічних наук, професор кафедри технології машинобудування і ремонту машин, Харківський національний автомобільно-дорожній університет, e-mail: khadi.pas@gmail.com

ПОДРИГАЛО Надія Михайлівна, доктор технічних наук, доцент кафедри інженерної i комп'ютерної графіки, Харківський національний автомобільно-дорожній університет, e-mail: ikg@khadi.kharkov.ua

БАЙЦУР Максим Вячеславович, кандидат технічних наук, доцент кафедри технології машинобудування і ремонту машин, Харківський національний автомобільно-дорожній університет, e-mail: tmirm@ukr.net

\section{АВТОРЫ:}

ПОДРИГАЛО Михаил Абович, доктор технических наук, заведующий кафедрой технологии машиностроения и ремонта машин, Харьковский национальный автомобильно-дорожный университет, e-mail: pmikhab@gmail.com

ПОЛЯНСБКИЙ Александр Сергеевич, доктор технических наук, профессор кафедры технологии машиностроения и ремонта машин, Харьковский национальный автомобильно-дорожный университет, e-mail: khadi.pas@gmail.com

ПОДРИГАЛО Надежда Михайловна, доктор технических наук, доцент кафедры инженерной и компьютерной графики, Харьковский национальный автомобильно-дорожный университет, е-тail: ikg@khadi.kharkov.ua

БАЙЦУР Максим Вячеславович, кандидат технических наук, доцент кафедры технологии машиностроения и ремонта машин, Харьковский национальный автомобильно-дорожный университет, e-mail: tmirm@ukr.net.

\section{AUTHORS:}

Mihail PODRIGALO, Doctor of Technical Sciences, Head of Mechanical Engineering and Machine Repair Technology department, Kharkiv National Automobile and Highway University, e-mail: pmikhab@gmail.com

Alexandr POLYANSKY, Doctor of Technical Sciences, Professor of Mechanical Engineering and Machine Repair Technology department, Kharkiv National Automobile and Highway University, e-mail: khadi.pas@gmail.com

Nadezhda PODRIGALO, Doctor of Technical Sciences, Associate Professor of Engineering and Computer Graphics department, Kharkiv National Automobile and Highway University, e-mail: ikg@khadi.kharkov.ua

Maxim BAYTSUR, Candidate of Technical Sciences, Associate Professor, Associate Professor of the Department of Mechanical Engineering and Machine Repair Technology, Kharkiv National Automobile and Highway University, e-mail: tmirm@ukr.net. 